\title{
Susanne Zepp \\ EI deseo de la palabra. \\ Sobre la relación entre la reflexión lingüística y la experiencia histórica en la obra de Alejandra Pizarnik
}

La confrontación con la reflexión del lenguaje poético, la comprensión de la poesía como una exploración del Yo mediante la exploración del lenguaje son, con motivo, temas esenciales de la confrontación literaria con la poetisa Alejandra Pizarnik, nacida en Buenos Aires en 1936. De hecho, Alejandra Pizarnik no sólo ha expresado en múltiples lugares a lo largo de su obra su voluntad inquebrantable de aprehender la percepción del mundo con el lenguaje, sino que también su obra se radicaliza hasta llegar a ser la única posibilidad de sobrevivir psíquica e incluso físicamente (Beneyto 1983; Rodríguez Francis 1996). La reflexión poética de los límites del lenguaje queda ya desde sus primeros trabajos literarios en el epicentro de su obra, y sobre todo también sus ensayos, diarios y sus otros textos en prosa apoyan, a través de afirmaciones explícitas sobre las posibilidades y limitaciones del lenguaje, su participación en la skepsis del lenguaje, típica de la modernidad tardía, como bien se ha visto en la investigación hasta la fecha de la obra de Pizarnik.

En el contexto de la crisis y pérdida del lenguaje, sobre todo se ha discutido qué estatus ha tenido el origen de la autora para sus textos. Las interpretaciones se alinean desde la suposición de una relación significativa del origen de Pizarnik en su trabajo literario, hasta una valoración de la insignificancia de éste para la obra literaria. Continuamente se trata la cuestión de si la obra de Alejandra Pizarnik contiene una dimensión central e inherentemente judía, o si por el contrario ésta es marginal y por eso hay que descartarla en su análisis (Borinsky 2000; Chávez-Silverman 1997; 2001; Campos 2005; Depetris 2001; Moia/Pensak 1983). 
La lectura de Pizarnik que me gustaría presentar sigue una estrategia diferente para comprender esta constelación temática y textual. Me gustaría proponer una interpretación de la relación entre la experiencia histórica de la autora y la forma de sus textos, para así intentar, no sólo poner al descubierto las particularidades que caracterizan los textos de Alejandra Pizarnik, sino que a partir de ahí podamos desarrollar ideas más generales sobre la relación entre la reflexión lingüística y la experiencia histórica.

Para esto me gustaría analizar la productividad del concepto de "identidad" como una categoría de análisis para los textos de Pizarnik, aunque posiblemente también para los textos literarios en general. La especialista en literatura Florinda Goldberg ya indicó el significado tan complejo que adquieren las cuestiones de origen y procedencia en la obra de Pizarnik: incluso cuando su procedencia judía se viva como una parte fundamental de su personalidad tan llena de matices, no hay figuraciones judías, a primera vista, en sus textos (Goldberg 1987). En este artículo, quiero tratar precisamente esta constelación.

En la lectura de los diarios de Alejandra Pizarnik se puede reconocer cuán compleja era la percepción de su propio origen y procedencia. ${ }^{1} \mathrm{Al}$ contrario que en sus escritos poéticos, se encuentran una y otra vez afirmaciones explícitas sobre su propio origen. Esto se muestra así por ejemplo en una anotación del diario de nuestra autora del 6 de septiembre de 1959, cuando sólo tenía 23 años:

1 Patricia Venti comentaba el hecho de que existe solamente una selección de los diarios de Pizarnik así (Venti 2004, sin paginación): "En el prólogo de la edición 2003 se dice lo siguiente: 'He tenido en cuenta el principio de respeto a la intimidad de terceras personas nombradas, aún vivas, y a la intimidad de la propia diarista y de su familia.' Los argumentos de Becciu no satisfacen el rigor de los criterios filológicos, ni tampoco las exigencias de una edición 'memorable'. En primer lugar porque no se sabe exactamente qué criterios sigue para excluir por completo fragmentos de la versión original por entradas corregidas por Pizarnik. El cuaderno que abarca los años '1962-1964', alega la editora, fue concebido para ser publicado y que 'podría considerarse la fase final de reescritura'; en vista de lo cual, la albacea literaria decide pegar los fragmentos trabajados al texto original, produciendo al final un collage o en el mejor de los casos un palimpsesto. En segundo lugar, como bien lo señala Nora Catelli, el carácter supuestamente hiriente de determinados pasajes no es razón suficiente para suprimirlos, si se tiene en cuenta que han transcurrido treinta años desde su fallecimiento. La mutilación de un corpus diarístico puede hacerse, pero ello a condición de anunciar y explicar los criterios de selección con claridad en el prólogo". 
Domingo 6 de septiembre 1959: Katherine Mansfield y V. Woolf. Vitalmente, o mortalmente, me siento más cerca de la primera. Dada mi situación y educación, jamás comprenderé, creo, la vida de una aristócrata inglesa. No obstante, he comprobado que mis poemas son más profundamente sentidos y vividos por personas de -digamos-clases altas que por las demás. Lo que sucede es que yo, como judía, no me considero de ninguna clase. Y jamás comprendería a quien despreciara mi origen. Es más: creo estar orgullosa de él (Pizarnik 2007: 147).

En 1934, algo menos de dos años antes de su nacimiento, emigraron los padres de Alejandra Pizarnik desde la ciudad ucraniana de Rovne hasta Argentina. La hija, Flora Pizarnik, quien más tarde cambiaría su nombre de pila por el de "Alejandra", pudo disfrutar de una educación liberal y orientada a las artes y la música, pero en la que también la tradición judía tuvo un lugar importante. Después de su graduación se mudó a Buenos Aires para estudiar Literatura y Artes, y muy pronto se dedicó exclusivamente a la escritura. Las corrientes existencialistas, simbolistas y surrealistas que había en los círculos literarios de la metrópolis argentina fueron una fuente de inspiración fundamental para los primeros poemas que empezó a publicar en distintas revistas (Lasarte 1983; Caulfield 1992; Muschietti 1997). En 1960, Pizarnik fue a París, ciudad donde permanecería cuatro años y donde no sólo se dio a conocer como traductora sino también como una renombrada poetisa. Cuando en 1962 se publicó su volumen Árbol de Diana, quedó instalada definitivamente en el Olimpo de la literatura latinoamericana (Gai 1992; Marín 2002). Tras su vuelta a Buenos Aires, Pizarnik empezó a luchar cada vez más contra sí misma. Los poemas y especialmente la prosa que, a partir de ese momento, empezó a escribir con más frecuencia, son testigos de sus intentos desesperados de ganar apoyo en una tradición a la que la historia siempre había marcado con el sello de la muerte, como ya formuló Anastasia Telaak en un comentario comprensivo sobre los poemas de Pizarnik (Telaak 2003a).

Casi todos los parientes de la familia Pizarnik que habían permanecido en Europa fueron asesinados por los alemanes. Tras la muerte de su padre, Alejandra Pizarnik trató el tema de su origen también en su trabajo literario aunque aisladamente, como en el texto en prosa Los muertos y la lluvia del año 1969, en el que se encuentran referencias intertextuales sobre el Midrasch y sobre la liturgia del Kaddisch, y motivos parecidos se pueden encontrar en otros textos de su trabajo 
literario de estos años hasta su suicidio, el 24 de septiembre de 1972 (Telaak 2003b).

Ante este panorama, ¿cómo podemos entender, entonces, el hecho de que Alejandra Pizarnik en sus textos poéticos le diera más importancia a la reflexión lingüística antes que a la confrontación literaria con su experiencia biográfica? Quiero acercarme a esta cuestión desde otra perspectiva. A continuación trataré de mostrar cómo Alejandra Pizarnik realza en forma de texto poético distintas constelaciones del origen en el lenguaje, que van más allá de la reflexión sobre el origen y la trayectoria vital de la autora, y que producirán su efecto en una reflexión sobre la experiencia histórica de una manera estética y genuinamente literaria.

Al meditar sobre la compleja relación entre origen, procedencia y representación literaria en los escritos de Pizarnik, se encuentran, finalmente, dos ámbitos. Por una parte, se plantea la cuestión, ante la pluralidad de escritos judíos, si en el fondo se puede hablar de una historia vertical y coherente de la literatura judía. ¿No se basa el concepto de una única cultura judía coherente en el espacio y el tiempo, en una manera de pensar esencialista? Se debe reconocer a los mundos de la vida judíos en su multiplicidad y pluralidad. No es el judaísmo como colectivo religioso y cultural lo que está en el centro de la reflexión de Alejandra Pizarnik, sino que más bien, lo que verdaderamente preocupa a Pizarnik es el modo de verse a sí misma, la propia imagen a través de categorías como religión y confesión, nacionalidad y ciudadanía, individuo y colectivo. Dedicarse a la obra literaria de Pizarnik exige, asimismo, reconocer tipos de literaturas que ni están dispuestas a renunciar a su esencia particular, ni están dispuestas a renunciar a su pertenencia a fenómenos y corrientes no-judíos. De aquí proviene la segunda pregunta fundamental, en este caso, de naturaleza teórica: posiblemente se manifiesta en los escritos de Pizarnik una particularidad de la literatura en sí que aquí se muestra como abstracción, y que quizá sólo pueda volverse realidad si se refracta en el prisma de lo particular, el cual extrae su propia naturalidad en relación al "otro", mientras redefine el Yo como el Otro.

En la discusión recientemente publicada entre Judith Butler y Gayatri Chakravorty Spivak bajo el nombre Who Sings the Nation-State? Language, Politics, Belonging (2007), se entiende la pertenencia sobre todo en el marco de la lógica nacional. A mi parecer es una tarea muy 
importante entender el origen y la pertenencia como una constelación hecha de múltiples capas, a la que pertenecen capas religiosas, capas relacionadas con el género, y también tradiciones literarias. La "identidad" como un concepto característico que intenta aprehender la singularidad diferenciadora del ser del individuo frente a otros, y de camino sugiere una unidad abarcadora, aparece al tener en cuenta esta pluralidad como un concepto atrofiante, denotando un vacío de creciente incertidumbre en la asignación de la pertenencia. Verena Dolle también indicaba esto en su introducción al simposio con la referencia a Stuart Hall, que entendió "identidad" como un dinámico proceso de construcción continuo. ${ }^{2}$

Alejandra Pizarnik expresa en las reflexiones poéticas de sus diarios esta convicción. Un ejemplo de ello es esta cita del año 1955:

5 de julio 1955. Pensando sobre la obra literaria. [...]. Heredé de mis antepasados las ansias de huir. Dicen que mi sangre es europea. Yo siento que cada glóbulo procede de un punto distinto. De cada nación, de cada provincia, de cada isla, golfo, accidente, archipiélago, oasis. De cada trozo de tierra o de mar han usurpado algo y así me formaron, condenándome a la eterna búsqueda de un lugar de origen. [...] Una de las preguntas que no puedo contestar: "Pero... ¿de dónde has salido tú que eres así?" (Pizarnik 2007: 30).

En este pasaje, Pizarnik une la obra poética con su origen, y lo hace de una manera en la que no se da una respuesta unívoca, sino que pone el movimiento de búsqueda en el centro de la estética. Para la búsqueda de su lugar, los símbolos del origen colectivo no tienen ningún valor epistemológico. Ciertamente, esto no es un fenómeno exclusivamente judío. Un discurso pluralista sobre el origen, en lugar de un discurso sobre la identidad, es una expresión universal de la modernidad. En este pasaje de los diarios se vive la experiencia del individuo suspendido que se aliena y se aleja del colectivo. De esta manera, absuelto, se entrega a la búsqueda de sí mismo. Para Pizarnik es la palabra formada, la poesía, el lugar en el que se le da una expresión artística a esta búsqueda. Es en la poesía como medio, donde se traspasan las limitaciones existentes en el mundo real, puesto que en ella, en la poesía, es el lugar donde se produce ese estado de la disolución total. La

2 "There is the production of self as an object in the world, the practices of selfconstitution, recognition and reflection, the relation to the rule, alongside the scrupulous attention to normative regulation, and the constraints of the rules without which no 'subjectification' is produced” (Hall 1996: 13). 
búsqueda de sí mismo es tras la pérdida del origen colectivo una búsqueda de la palabra, del lenguaje, a la que el individuo se expone desnudo y desprotegido.

El análisis que acabamos de hacer de la lectura de los diarios encuentra su correspondencia en la poesía. Por tanto, me gustaría presentar y comentar en este artículo también dos poemas de Alejandra Pizarnik.

Se trata de textos poéticos de distintas épocas en la obra de Alejandra Pizarnik. El primer texto pertenece a una colección que fue publicada en el año 1958 bajo el título Las aventuras perdidas. El poema tiene por nombre "Origen", y ya en este texto de la poetisa, que por aquel entonces tenía 22 años, se encuentra a mi parecer la conexión programática de origen y reflexión lingüística en la poesía de Pizarnik.

\section{Origen}

La luz es demasiado grande para mi infancia.

Pero ¿quién me dará la respuesta jamás usada?

Alguna palabra que me ampare del viento, alguna verdad pequeña en que sentarme y desde la cual vivirme, alguna frase solamente mía que yo abrace cada noche, en la que me reconozca, en la que me exista.

Pero no. Mi infancia

sólo comprende al viento feroz

que me aventó al frío cuando campanas muertas me anunciaron.

Sólo una melodía vieja, algo con niños de oro, con alas de piel verde, caliente, sabio como el mar, que tirita desde mi sangre, que renueva mi cansancio de otras edades.

Sólo la decisión de ser dios hasta en el llanto (Pizarnik 2009: 88).

Ya en este temprano poema se encuentra evocada esta constelación fundamental que es la que trato de analizar en este ensayo: la palabra poética se coloca como respuesta a la pregunta hecha en el verso nú- 
mero tres en medio del poema, que está dedicado tanto por su título como por los primeros dos versos al tema del origen.

En este texto, el Yo se convierte en una metáfora poetológica en el espacio de la poesía y de esta manera abre un campo magnético de vivencia interna como de proyección lingüística. Frecuentemente Pizarnik ha definido el poema como una representación del origen. Al pronunciar la palabra "infancia" dos veces queda contenida esta conexión personal también en el texto. Pero, ¿qué es lo que propiamente se dice sobre el tema anunciado en el título, el origen? Una determinación unívoca resulta difícil: la infancia está determinada primero por una luz demasiado grande, en la segunda alusión por un viento feroz, mientras la palabra protege al Yo lírico del viento y el vivirse a sí mismo sólo puede efectuarse desde el lenguaje -véanse los versos seis y siete. Los dos últimos versos de la primera estrofa hacen crecer el significado de la palabra y del lenguaje hasta llegar a ser la única posibilidad de poder conocerse a sí mismo y de la existencia en sí.

De esta manera, la infancia se entiende, en oposición, como algo que sólo entiende el viento feroz donde campanas muertas suenan. Así es este poema de título "Origen" propiamente un poema sobre la elección de otro origen - distinto del biográfico. En todo caso, Pizarnik elude la cuestión sobre esta obviedad. Esto lo consigue sobre todo mediante la representación de una búsqueda que no halla su final. El Yo, el origen, queda alienado por el Yo poético, mientras al mismo tiempo se articula una nostalgia de un reconocimiento de sí mismo en el poema.

Es un hecho destacable que el último verso de este poema se haya dejado de lado en muchas antologías y en algunas interpretaciones. Después de que en la última estrofa se conjure el recuerdo a un tiempo pasado y perdido, el mundo de la infancia con sus cuentos, acaba el poema con un verso en el que el Yo poético muestra su decisión -aquélla de querer ser Dios hasta llorar. Esta perspectiva de la poetisa como Dios evoca la representación del poema como heterocosmos. Desde mi punto de vista, este texto, y concretamente el último verso, contiene el núcleo de la estética de Pizarnik, y a su vez la respuesta a la pregunta hecha al principio de por qué, a pesar de mostrar una reflexión intensa sobre su origen en los diarios, los textos poéticos sólo son indicadores de señales difusas sobre el origen. La obra de Pizarnik se sale del continuo de la realidad e intenta crear un mundo paralelo 
en el que se equilibran los defectos del primero, ya que éste se conforma, independientemente, de ella. Esta creación artística queda representada ni más ni menos como la repetición del acto divino de la creación en el espíritu finito y humano. El llanto, la queja, que se nombra en la última palabra del poema: "llanto", hace referencia a los continuos intentos fallidos. El salirse del contexto del mundo real a través de la poesía es para Pizarnik un acto de fracaso productivo por culpa de las limitaciones del lenguaje. La perfección esperada del mundo poético queda en la forma y el procedimiento de la obra de Pizarnik rota de tal manera que ella misma se vuelve a acercar a la experiencia del mundo real, ese mismo mundo del que el lenguaje debía deportarla.

Esta dualidad caracteriza la obra de Pizarnik. Su imaginación es movimiento entre los dos mundos, y así evocan los niños de oro y seres de verdes alas del verso 16 no sólo los cuentos de la infancia, sino también los verdes y dorados mundos ideales de la literatura, a los que Pizarnik siente que pertenece. En este sentido, los poemas de Pizarnik son proyectos del Dasein, ya que hacen surgir del lenguaje un espacio que no sólo tiene significado estético sino también existencial.

En sus referencias a textos de otros autores, en la integración de voces ajenas en su propia obra se trata de integración y parentesco, pero también de encuentros consigo misma en un tanteo con la posibilidad de lo humano. El modelo poetológico fundamental que a partir de este poema se ha de analizar, ofrece una estructura doble: junto a una sincronizante y fusionada participación en la tradición de la poesía europea, se trata al mismo tiempo de una extrema concentración lingüística particular.

Me gustaría reproducir este concepto en un último poema para entenderlo mejor. El segundo texto poético que he seleccionado es el poema en prosa "El deseo de la palabra". Se trata de un texto poético estructurado en seis estrofas en prosa. El poema pertenece a la colección El infierno musical, publicado en el año 1971.

\section{EI deseo de la palabra}

I. La noche, de nuevo la noche, la magistral sapiencia de lo oscuro, el cálido roce de la muerte, un instante de éxtasis para mí, heredera de todo jardín prohibido.

II. Pasos y voces del lado sombrío del jardín. Risas en el interior de las paredes. No vayas a creer que están vivos. No vayas a creer que no 
están vivos. En cualquier momento la fisura en la pared y el súbito desbandarse de las niñas que fui.

III. Caen niñas de papel de variados colores. ¿Hablan los colores? ¿Hablan las imágenes de papel? Solamente hablan las doradas y de ésas no hay ninguna por aquí.

IV. Voy entre muros que se acercan, que se juntan. Toda la noche hasta la aurora salmodiaba: "Si no vino es porque no vino". Pregunto. ¿A quién? Dice que pregunta, quiere saber a quién pregunta. Tú ya no hablas con nadie. Extranjera a muerte está muriéndose. Otro es el lenguaje de los agonizantes.

V. He malgastado el don de transfigurar a los prohibidos (los siento respirar adentro de las paredes). Imposible narrar mi día, mi vía. Pero contempla absolutamente sola la desnudez de estos muros. Ninguna flor crece ni crecerá del milagro. A pan y agua toda la vida.

VI. En la cima de la alegría he declarado acerca de una música jamás oída. ¿Y qué? Ojalá pudiera vivir solamente en éxtasis, haciendo el cuerpo del poema con mi cuerpo, rescatando cada frase con mis días y con mis semanas, infundiéndole al poema mi soplo a medida que cada letra de cada palabra haya sido sacrificada en las ceremonias del vivir (Pizarnik 2009: 269-270).

La primera estrofa de este poema coloca dos imágenes en primer plano: la noche y el jardín. El Yo-poeta se presenta no como heredero de una herencia familiar, de una tierra o una patria, sino como heredero del jardín prohibido. El jardín es en la obra de Pizarnik un símbolo para el lugar común de la poesía (Campos 2005). La inserción lingüística del jardín prohibido evoca a la vez al jardín del Edén y a la vida en el paraíso tal y como se entiende en el lenguaje universal. La noche es desde el romanticismo un símbolo para el tiempo de la revelación y el conocimiento, que puede liberar y absolver y finalmente también un símbolo para la muerte o la nostalgia por ésta. Precisamente a estos dos significados del símbolo se hace referencia en el texto: la magistral sapiencia de lo oscuro, el cálido roce de la muerte. Objeto de este poema es también el lenguaje moldeado artísticamente.

La fisura que pivota en el centro de la segunda estrofa evoca aquella particularidad en la recepción poética: al leer se aparecen de una vez, casi de manera súbita, las cosas de este mundo que rodean al receptor del texto poético; ya sea con sentido completo o bajo una nueva luz, se sorprende uno, ciertamente, por la impresión de entender algo que sólo puede comprenderse más tarde de una manera reflexiva. Este acontecimiento tiene la forma de una "fisura" que por un momento se 
abre y que surge de un momento custodiado por el lenguaje. El reto de comprender este momento marca la tercera estrofa de este poema.

La cuarta y la quinta parte miden los espacios del texto que van desde la Biblia hasta la poesía y la filosofía del siglo XX, y que gracias a las referencias poéticas, literarias y culturales se materializan. Pizarnik conecta la palabra religiosamente impregnada del Salmo con la desesperación de una poetisa que teme fracasar en su propia poesía, que se ve incapaz de transformar la vivencia en lenguaje. Este miedo traspasa todas las capas del material lingüístico, se anida donde quiera que se encuentren acontecimientos que puedan salvarse en forma de poema; detener el tiempo, concentrarlo y ralentizarlo; engrandecer cosas, empequeñecerlas, conectar, por precisarlo fenomenológicamente.

La última parte del poema habla del momento extraño en el que el Yo-poeta tuvo la impresión de no fracasar en la conversión al lenguaje. La embriaguez del texto se basa en una combinación impredecible de posibilidades del Yo, del lenguaje y de la ya existente poesía. Por eso se muestra precisamente ahí, donde la transformación ocurre, en el poema -que se conoce como la especie literaria más fragmentariacomo parte de la poetisa, como su cuerpo. Ella se convierte en letra, se convierte en otra cosa, siempre en algo nuevo.

Los poemas de Alejandra Pizarnik se resisten a una exegesis directa. No hacen un recorrido lineal, no se mueven palabra por palabra. Más bien se exponen ante el lector como una red complicada de detalles semánticos. Juegos de palabras, alusiones personales escondidas, citas falsas a propósito, neologismos extraños: éste es el material que fluye en los poemas de Pizarnik. No hay en su obra nada casual, nada de más que pudiese obstruir la mirada al poema. Uno lee ciertamente con la piel, como por ósmosis, de manera inconsciente se absorben matices, tonos mezclados, saltos sintácticos que por sí mismos componen el sentido del poema, tanto como su contenido analítico. Alejandra Pizarnik ha intentado en su trabajo poético inscribirse a sí misma -su propia vida y su propio cuerpo- por completo en el lenguaje (Foster 1994). El poema "El deseo de la palabra" es ejemplo de ello.

Me gustaría desarrollar como punto de partida para la última parte de mi artículo una de las reflexiones poetológicas de Pizarnik más explícitamente. Me gustaría llevarlo a cabo planteando la cuestión acerca del significado de su proyecto estético para la historia de la literatura en general, y esto, como ya anuncié, con perspectiva a la 
relación entre la reflexión lingüística y la experiencia histórica. En 1968, Alejandra Pizarnik escribió un prólogo para una antología de poesía argentina contemporánea bajo el título programático "El poeta y su poema". La cita siguiente pertenece a este texto:

La poesía es el lugar donde todo sucede. A semejanza del amor, del humor, del suicidio y de todo acto profundamente subversivo, la poesía se desentiende de lo que no es su libertad o su verdad. Decir libertad o verdad y referir estas palabras al mundo en que vivimos o no vivimos es decir una mentira. No lo es cuando se atribuye a la poesía: lugar donde todo es posible. [...]. En oposición al sentimiento de exilio, al de una espera perpetua está el poema -tierra prometida (Pizarnik 1999: 367).

Querer encontrar la identidad de un poeta es un encargo sumamente complicado, si no imposible. Esta sentencia vale para Alejandra Pizarnik en gran medida, ya que se resiste a cualquier modelo de identidad que se le haya atribuido -no sólo porque la identidad es algo unitario, sino también en caso de que la entendamos como una estructura movible y abierta (Bollig 2009). Como cualquier otra escritora, Alejandra Pizarnik elaboró su propia búsqueda de la identidad en confrontación con el lenguaje y a través de éste. ${ }^{3}$ Para Alejandra Pizarnik el poema es el lugar donde se reúne todo aquello percibido y alcanzado por el lenguaje, el lugar en el que gana forma y verdad.

Frente a este posicionamiento absoluto se plantea la pregunta de cómo un lector puede satisfacer la realidad autónoma del texto y al mismo tiempo las referencias a las experiencias históricas a las que Pizarnik se refiere. Alejandra Pizarnik une en su obra todo aquello que las distintas escuelas de la literatura suelen separar: por una parte, el texto comprensible por sí solo o incluso incomprensible, y, por otro lado, el contexto biográfico. Para Pizarnik la hermética de sus textos puede y debe ser comprendida por una parte en la inmanencia de sus complejas referencias lingüísticas $\mathrm{y}$, por la otra, en la restitución que

3 Marta López-Luaces comentaba este hecho de la forma siguiente: "El deseo de unir poesía y vida, como ya deseaban los surrealistas, se transforma en su obra en una reflexión sobre la identidad poética y su incoherencia. Para ella esta identidad, una identidad puramente poética, implica una reflexión sobre la muerte, la infancia y la locura, motivos por otra parte comunes en la literatura. Estos motivos se han asociado más íntimamente con los románticos, los surrealistas y los llamados poetas malditos, con los que Pizarnik siente una gran afinidad. En ella hay una conciencia de querer insertarse dentro de un discurso en que se cuestiona la fragmentación del yo poético y se reafirma a la vez que cuestiona la identidad del/a poeta" (López Luaces 2002, sin paginación). 
las experiencias biográficas viven en el medio del lenguaje. Es justamente lo que concretamente se reconstruye cada vez, ya sea lo particular o lo individual, lo que no se integra en cualquier discurso general, sino que se trabaja lingüísticamente, y en este trabajo queda así custodiado en el archivo de los textos como testigo.

Ahora sólo queda por entender por qué Pizarnik comprende el poema como el lugar donde todo acontece, y por qué sus textos no se pueden descifrar solamente con la búsqueda binaria de motivos, ya sean judíos o universales. El proceso poético constituye el núcleo de la percepción estética. Es esto justamente lo que indica la última frase aquí citada: contrario al sentimiento del exilio, el sentimiento de la espera eterna, es la poesía, la tierra prometida. Esta tierra es sólo verdadera en la expresión consciente y fragmentaria que queda en la frontera, entre las múltiples identidades culturales y cuyas características quedan mezcladas entre ellas sin llegar a querer formar una síntesis. En la búsqueda tras la expresión poética se divide la poesía de Pizarnik en momentos únicos, en vez de formar una serie continua que se suma en una unidad. Los abismos del lenguaje, la indisponibilidad de la palabra adecuada juegan un papel estructural, y no por puro vacío sino por fuerza creadora. Estas tensiones determinan la poesía de Pizarnik, que sólo son legibles de una manera adecuada teniendo en cuenta todos estos elementos de discontinuidad, huecos y, en parte, contradicciones. La escritura lleva consigo la decisión imposible entre expresión y verdad, entre palabras y cosas. La tierra prometida de todas las poesías desde la que el proceso poético crea, y las aporías de una forma de escribir judía en Alejandra Pizarnik quedan de manera metonímica contenidas en las aporías de la poesía en sí.

Alejandra Pizarnik ha sido calificada hasta hoy sobre todo como una voz surrealista, judía o feminista (Álvarez 1997; De Cicco 1997; Calafell Sala 2007; Galvin 2007; Genovese 1996; Kirkpatrick 1996; Kroll 2008). Pero su lucha desesperada alrededor del lenguaje, su confrontación intensiva con la tradición literaria y la traslación de la pregunta sobre su origen al plano del texto son los rasgos universales de una poetisa que entendió su escritura como un experimento poetológico continuo y reflexivo con el lenguaje. Sus poemas están caracterizados por una mezcla de la crítica más amarga y la utopía más nostálgica, con la que se topaba una y otra vez con la mayor admiración y en parte también con una gran incomprensión. 
Por esto mismo la obra poética de Pizarnik mantiene precisamente ese difícil equilibrio entre la reflexión lingüística y la experiencia histórica. Así, la poesía de Alejandra Pizarnik tiene la capacidad de exigirle al discurso literario que salga adelante sin valores normativos. Esto no quiere decir que se renuncie a un juicio de valor comprometido. Un discurso crítico y relativista que niegue cualquier norma o posibilidad de preferencia o rechazo se resiste a cualquier valoración. No obstante, el valor del discurso no queda forzosamente determinado por aquello que a priori es fiel a cualquier categoría conceptual, abstracta o superpuesta (lo "judío", lo "moderno", lo "femenino", etc.), sino que es fiel a la poesía misma y a las ambigüedades indicadas por la experiencia. La interpretación de textos literarios es un cuestionar y responder en un procedimiento de diálogo en el que se escuchan y se deben escuchar múltiples voces. El diálogo contenido en la poesía de Alejandra Pizarnik entre el origen, la tradición literaria y la experiencia histórica no sólo estimula, sino que obliga al lector a escucharlas. De esta manera, la obra de Pizarnik es particular y universal al mismo tiempo, y así se puede entender como un sismógrafo de la modernidad y sus rechazos.

\section{Bibliografía}

Álvarez, Enid (1997): “A medida que la noche avanza”. En: Debate Feminista, 8, 15, pp. 3-34.

Bajarlia, Juan-Jacobo (1998): Alejandra Pizarnik: anatomía de un recuerdo. Buenos Aires: Almagesto.

Beneyto, Antonio (1983): “Alejandra Pizarnik: ocultándose en el lenguaje”. En: Quimera: Revista de Literatura, 34, pp. 23-27.

Bollig, Ben (2009): "How Many Ways to Leave your Country? On Exile and NotBelonging in the Work of Alejandra Pizarnik". En: Modern Language Review, 104, 2, pp. 421-437.

Borinsky, Alicia (1995): “Alejandra Pizarnik: The Self and Its Impossible Landscapes". En: Agosín, Marjorie (ed.): A Dream of Light and Shadow. Portraits of Latin American Women Writers. Albuquerque: University of New Mexico Press, pp. 291-302.

- (2000): "Memoria del vacío: Una nota personal en torno a la escritura y las raíces judías". En: Revista Iberoamericana, 66, 191, pp. 409-412.

Butler, Judith/Chakravorty Spivak, Gayatri (2007): Who Sings the Nation-State? Language, Politics, Belonging. London: Seagull Books. 
Calafell Sala, Nuria (2007): “Textualidades femeninas: La auto(bio)grafía en Victoria Ocampo, Norah Lange y Alejandra Pizarnik”. En: Extravío: Revista Electrónica de Literatura Comparada, 2, pp. 89-103.

Campos, Dores Tembras (2005): "Biografía poética de Alejandra Pizarnik a través de sus símbolos". En: Moderna Sprak, 99, 1, pp. 96-110.

Caulfield, Carlota (1992): "Entre la poesía y la pintura: Elementos surrealistas en Extracción de la piedra de locura y El infierno musical”. En: Chasqui: Revista de Literatura Latinoamericana, 21, 1, pp. 3-10.

Chávez Silverman, Suzanne (1990): "The Discourse of Madness in the Poetry of Alejandra Pizarnik". En: Monographic Review/Revista Monográfica, 6, pp. 274281.

- (1997): "The Autobiographical as Horror in the Poetry of Alejandra Pizarnik". En: Covi, Giovanna (ed.): Critical Studies on the Feminist Subject. Trento: Dipartimento di Scienze Filologiche e Storiche, Universita degli Studi di Trento, pp. 265-277.

- (2001): "The Poetry of Octavio Paz and Alejandra Pizarnik: A Dialogue with Silence". En: Armistead, Samuel G./Caspi, Mishael M. (eds.): Jewish Culture and the Hispanic World: Essays in Memory of Joseph H. Silverman. Newark: Cuesta, pp. 129-144.

- (2006): "Trac(k)ing Gender and Sexuality in the Writing of Alejandra Pizarnik". En: Chasqui, 35, 2, pp. 89-108.

De Cicco, Gabriela (1997): “Alejandra revisited”. En: Debate Feminista, 8, 15, pp. 35-39.

Depetris, Carolina (2001): "Reflexiones sobre el hacer poético: Conflicto ontológico en Alejandra Pizarnik". En: Mester, 30, pp. 35-51.

- (2008): “Alejandra Pizarnik después de 1968: La palabra instantánea y la "crueldad' poética”. En: Iberoamericana, 8, 31, pp. 61-76.

DiAntonio, Robert E. (1987): "On Seeing Things Darkly in the Poetry of Alejandra Pizarnik: Confessional Poetics or Aesthetic Metaphor?” En: Confluencia, 2, 2 , pp. 47-52.

Foster, David William (1994): "The Representation of the Body in the Poetry of Alejandra Pizarnik". En: Hispanic Review, 62, 3, pp. 319-347.

Gai, Michal Heidi (1992): “Alejandra Pizarnik: Árbol de Diana”. En: Romanic Review, 83, 2, pp. 245-260.

Galvin, Rachel (2007): “El 'Gran Silencio' de Alejandra Pizarnik”. En: Guardia, Sara Beatriz (ed.): Mujeres que escriben en América Latina. Lima: Centro de Estudios La Mujer en la Historia de América Latina, pp. 365-371.

García-Moreno, Laura (1996): "Alejandra Pizarnik and the Inhospitability of Language: The Poet as Hostage". En: Latin American Literary Review, 24, 48, pp. 67-93.

Genovese, Alicia (1996): “La viajera en el desierto”. En: Feminaria Literaria, 6, 10, pp. 10-11.

Goldberg, Florinda (1987): “Alejandra Pizarnik: Palabra y sombra”. En: Noah: Revista Literaria, 1, 1, pp. 58-62. 
- (1994): Alejandra Pizarnik: "Este espacio que somos". Gaithersburg: Hispamérica.

Hall, Stuart (1996): “Introduction. Who Needs Identity?”. En: Hall, Stuart/Du Gay, Paul (eds.): Questions of Cultural Identity. London: Sage, pp. 1-17.

Kirkpatrick, Gwen (1996): “Alejandra Pizarnik como sitio de refugio”. En: Feminaria Literaria, pp. 13-17.

Ko, Teresa (2004): “Alejandra Pizarnik, la muñeca rusa: Ensayo sobre el ensimismamiento y el acto de 'entrar' en la poesía de Pizarnik". En: Tinta, 8, pp. 65-81.

Kroll, Juli A. (2008): “Conciencia desdoblada: Agencia femenina y melancolía en la poesía de Alfonsina Storni, Rosario Castellanos, y Alejandra Pizarnik”. En: Hispanic Journal, 29, 2, pp. 69-85.

Lasarte, Francisco (1983): "Mas allá del surrealismo: La poesía de Alejandra Pizarnik". En: Revista Iberoamericana, 49, 125, pp. 867-877.

López Luaces, Marta (2002): "Los discursos poéticos en la obra de Alejandra Pizarnik". En: <www.ucm.es/info/especulo/numero21/index.html> (10.11.2010).

Marín, Paola (2002): "Lenguaje y representación en Árbol de Diana". En: Romance Notes, 42, 3, pp. 341-348.

Martínez, Z. Nelly (2003): "Alejandra Pizarnik (29 April 1936-25 September 1972)". En: Salgado, María A. (ed.): Modern Spanish American Poets: First Series. Detroit: Gale, pp. 295-304.

Moga, Eduardo (2001): "Hablar del silencio". En: Lateral: Revista de Cultura, 8, 7980, pp. 12-13.

Moia, Martha I./Pensak, Susan (1983): "Some Keys to Alejandra Pizarnik". En: Sulfur, 8, pp. 97-101.

Muschietti, Delfina (1989): “Alejandra Pizarnik: La niña asesinada”. En: Filología, 24, 1-2, pp. 231-241.

- (1995): "Poesía y paisaje: Exceso e infinito". En: Cuadernos Hispanoamericanos, 538, pp. 81-88.

- (1997): "La conexión Trakl-Pizarnik: Transformación del modelo gemelar". En: Filología, 30, 1-2, pp. 255-264.

Negroni, María (2000): “Alejandra Pizarnik: Melancolía y cadáver textual”. En: Inti: Revista de Literatura Hispánica, 52-53, pp. 169-178.

Peri Rossi, Cristina (1973): “Alejandra Pizarnik o la tentación de la muerte". En: Cuadernos Hispanoamericanos: Revista Mensual de Cultura Hispánica, 273, pp. 584-588.

Piña, Cristina (1990): "La palabra obscena". En: Cuadernos Hispanoamericanos: Revista Mensual de Cultura Hispánica, sup. Los Complementarios, 5, pp. 17-38.

- (1991): Alejandra Pizarnik. Buenos Aires: Planeta.

- (2007): "Poder, escritura y edición: Algunas reflexiones acerca de la Poesía completa, la Prosa completa y los Diarios de Alejandra Pizarnik”. En: Páginas de Guarda, 3, pp. 61-77. 
Pizarnik, Alejandra ([1968] 1999): "El poeta y su poema". En: Pizarnik, Alejandra: Obras completas: poesía completa y prosa selecta. Edición de Cristina Piña. Buenos Aires: Ediciones Corregidor, p. 367.

- (2007): Diarios. Edición a cargo de Ana Becciú. Barcelona: Editorial Lumen.

- (2009): Poesía completa. Edición a cargo de Ana Becciú. Barcelona: Editorial Lumen.

Polizzi, Assunta (1994): "La palabra y el silencio: la poesía de Alejandra Pizarnik". En: Cincinnati Romance Review, 13, pp. 106-112.

Rodríguez Francis, Ana María (1996): “Cuestionamiento del lenguaje en la poesía en prosa argentina: Alejandra Pizarnik y Maria Ross Lojo”. En: Letras, 34, pp. 123139.

Rosenvinge, Teresa (2009): "La oscuridad que aún brilla en las de Olga Orozco y Alejandra Pizarnik". En: Cuadernos Hispanoamericanos, 707, pp. 31-37.

Sefami, Jacobo (1994): "Vacío gris es mi nombre mi pronombre: Alejandra Pizarnik". En: Inti: Revista de Literatura Hispánica, 39, pp. 111-118.

Tamargo, Maribel (1994): "La poesía de Alejandra Pizarnik”. En: Confluencia: Revista Hispánica de Cultura y Literatura, 9, 2, pp. 33-37.

Telaak, Anastasia (2003a): “Könnte ich doch nur in Ekstase leben ...': Alejandra Pizarniks 'Schrecklich exakte Gedichte'”. En: die horen: Zeitschrift für Literatur, Kunst und Kritik, 48, 4, 212, pp. 177-185.

- (2003b): Körper, Sprache, Tradition: jüdische Topographien im Werk zeitgenössischer Autorinnen und Autoren aus Argentinien. Berlin: WVB.

Venti, Patricia (2004): "Los diarios de Alejandra Pizarnik: censura y traición". En: $<$ www.ucm.es/info/especulo/numero26/diariosp.html> (10.11.2010).

- (2005): "Palais du vocabulaire de Alejandra Pizarnik: cuadernos de notas o apuntes para sobrevivir". En: <www.ucm.es/info/especulo/numero31/palaisap. html> (10.11.2010). 